\title{
Biomechanical evidence suggests extensive eggshell thinning during incubation in the Sanagasta titanosaur dinosaurs
}

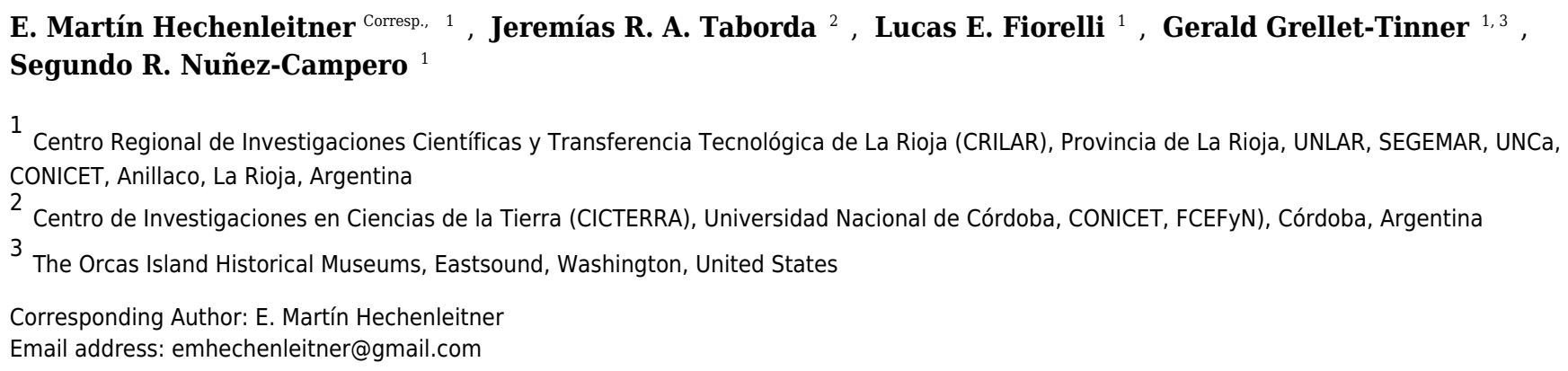

The reproduction of titanosaur dinosaurs is still a complex and debated topic. Their Late Cretaceous nesting sites are distributed worldwide and their eggs display substantial morphological variations according to the parent species. In contrast to the typical 1.3-2.0 $\mathrm{mm}$-thick shells common to eggs of most titanosaur species (e.g. those that nested in Auca Mahuevo, Tama, Toteşti or Boseong), the Cretaceous Sanagasta eggs of Argentina display an unusual shell thickness of up to $7.9 \mathrm{~mm}$. Their oviposition was synchronous with a palaeogeothermal process, leading to the hypothesis that their extra thick eggshell was an adaptation to this particuliar nesting environment. Although this hypothesis has already been supported indirectly through several investigations, the mechanical implications of developing such thick shells and how this might have affected the success of hatching remained untested. Finite element analyses estimate that the breaking point of the thickshelled Sanagasta eggs is 14-45 times higher than for other smaller and equally sized titanosaur eggs. The considerable energetic disadvantage for pipping through these thick eggshells suggests that their dissolution during incubation would have been paramount for a successful hatching. 

incubation in the Sanagasta titanosaur dinosaurs

E. Martín Hechenleitner ${ }^{1 *}$, Jeremías R. A. Taborda ${ }^{2}$, Lucas E. Fiorelli ${ }^{1}$, Gerald Grellet-Tinner ${ }^{1,3}$, Segundo R. Nuñez-

${ }^{1}$ Centro Regional de Investigaciones Científicas y Transferencia Tecnológica de La Rioja (CRILAR), Provincia de

6 La Rioja, UNLAR, SEGEMAR, UNCa, CONICET. Entre Ríos y Mendoza s/n, (5301) Anillaco, La Rioja

7 (Argentina).

$8{ }^{2}$ Centro de Investigaciones en Ciencias de la Tierra (CICTERRA), Universidad Nacional de Córdoba, CONICET,

9 FCEFyN, Vélez Sarsfield 1611, Ciudad Universitaria, X5016GCA Córdoba, Argentina.

$10{ }^{3}$ The Orcas Island Historical Museums, Eastsound, Washington, USA.

$11 *$ Corresponding author: emhechenleitner@gmail.com 


\section{Abstract}

14 The reproduction of titanosaur dinosaurs is still a complex and debated topic. Their Late Cretaceous

15 nesting sites are distributed worldwide and their eggs display substantial morphological variations

16 according to the parent species. In contrast to the typical 1.3-2.0 mm-thick shells common to eggs of most

17 titanosaur species (e.g. those that nested in Auca Mahuevo, Tama, Toteşti or Boseong), the Cretaceous

18 Sanagasta eggs of Argentina display an unusual shell thickness of up to $7.9 \mathrm{~mm}$. Their oviposition was

19 synchronous with a palaeogeothermal process, leading to the hypothesis that their extra thick eggshell

20 was an adaptation to this particuliar nesting environment. Although this hypothesis has already been

21 supported indirectly through several investigations, the mechanical implications of developing such thick

22 shells and how this might have affected the success of hatching remained untested. Finite element

23 analyses estimate that the breaking point of the thick-shelled Sanagasta eggs is 14-45 times higher than

24 for other smaller and equally sized titanosaur eggs. The considerable energetic disadvantage for pipping

25 through these thick eggshells suggests that their dissolution during incubation would have been

26 paramount for a successful hatching.

27 


\section{INTRODUCTION}

Recent studies have changed our perspective on titanosaur palaeobiology. These highly diversified dinosaurs were the largest terrestrial organisms that ever roamed the earth and, according to recent investigations, their thermophysiology was similar to that of large modern endotherms (Seymour et al., 2012; Seymour, 2013; Eagle et al., 2015). Titanosaur eggs were incubated in holes excavated in the soil or in mounds of soil and leaf litter, comparable to the nests of the modern megapodes (Grellet-Tinner \& Fiorelli, 2010; Hechenleitner, Grellet-Tinner \& Fiorelli, 2015) and their chicks had a rapid ontogenetic development (Werner \& Griebeler, 2014; Curry Rogers et al., 2016). Perinatal embryos preserved in ovo also revealed that titanosaurs developed an "egg-tooth"-like structure (García, 2007) that could have served to break the shell during hatching. Such anatomical structure is present in all the archosaurs (from crocodilians to birds) and presently, is the only known to be specifically involved in the hatching process (Honza et al., 2001; García, 2007; Hieronymus \& Witmer, 2010; Hermyt et al., 2017).

Titanosaurs laid amniotic eggs with a calcitic shell. This genetically and physiologically-controlled, biomineralized hard layer that protects the developing embryo from damage (mechanical or chemical), dehydration and infection, is specifically adapted to particular nesting environments, hence functionally optimized for each species (Ferguson, 1981; Board, 1982). Titanosaur eggshells consist of monolayered calcium carbonate, growing from densely packed shell units of rhombohedric, acicular calcite crystals that radiate from nucleation centres located at the external surface of the membrana testacea (GrelletTinner, Chiappe \& Coria, 2004). Although titanosaur eggshells typically are $1.35-2.0 \mathrm{~mm}$ thick, the exceptionally thick-shelled eggs of the Sanagasta nesting site, in La Rioja, Argentina, reach $7.9 \mathrm{~mm}$ (Grellet-Tinner \& Fiorelli, 2010; Grellet-Tinner, Fiorelli \& Salvador, 2012; Hechenleitner et al., 2016a) (Table 1).

At Sanagasta, more than 80 titanosaur egg clutches were found to be synchronous with a Cretaceous geothermal process (Grellet-Tinner \& Fiorelli, 2010; Fiorelli et al., 2012). Although unique among non-avian dinosaurs, the evidence at hand suggests that several species of titanosaurs may have utilized geothermalism as a source of heat for egg incubation (Grellet-Tinner \& Fiorelli, 2010; 
55 Hechenleitner, Grellet-Tinner \& Fiorelli, 2015). Yet, nesting in active geothermal settings is still a

56 strategy exploited by several modern vertebrates, chiefly iguanas, snakes, birds, and even deep-sea skates

57 (Werner, 1983; Göth \& Vogel, 1997; Guo et al., 2008; Salinas-de-León et al., 2018), because it ensures a

58 nesting thermal stability. Such association between titanosaur nesting and palaeogeothermalism led to

59 hypotheses that thickness of the Sanagasta eggshells was an adaptation to resist the extrinsic dissolution

60 by pore fluids in a harsh nesting environment (Grellet-Tinner \& Fiorelli, 2010; Grellet-Tinner, Fiorelli \&

61 Salvador, 2012). This hypothesis received additional paleobiological support from more recent studies on

62 the striking thickness of these eggshells (Grellet-Tinner, Fiorelli \& Salvador, 2012; Hechenleitner et al.,

63 2016a). The new data confirmed that these titanosaur eggs were physiologically functional; that is, they

64 would have allowed an appropriate gas exchange under burial conditions in the substrate, even when their

65 shells were as thick as $7.9 \mathrm{~mm}$. Moreover, calculations based on micro-CT data showed that the eggshells

66 were also physiologically functional even when they thinned up to $80 \%$ or $1.5 \mathrm{~mm}$ (Hechenleitner et al.,

67 2016a). This implies that the suggested external chemical erosion of the shell by hydrothermal fluids

68 would not have compromised the incubation with respect to gas exchange. However, whether or not this

69 dissolution of the shell was essential for the hatchability of the Sanagasta eggs (as well as other titanosaur eggs) is a hypothesis that has not yet been tested.

Therefore, the present investigation aims to test the mechanical strength of the Sanagasta eggs using FEA on models of titanosaur eggs from several nesting sites by evaluating the required force to break them from inside. Furthermore, it will shed light on the importance of the external dissolution of the shell by chemical leaching, and its paramount role for their hatchability and the survival of several titanosaur species.

\section{METHODS}

\section{Specimens and modelling}

We analysed data of Haţeg (Romania), Boseong (South Korea), Tama, Sanagasta, and Auca 
81 obtained from digital 3D reconstructions of specimens curated at the Centro Regional de Investigaciones

82 Científicas y Transferencia Tecnológica de La Rioja (CRILAR-PV 530/1 and CRILAR-PV 400 SA-C6-

83 e1, respectively). Egg models for other sites are based on personal observations (Haţeg and Auca

84 Mahuevo) and literature (Boseong) (Hechenleitner, Grellet-Tinner \& Fiorelli, 2015; Hechenleitner et al., 85 2016b). In addition, we included data from Hahn et al. (2017) for four kinds of living birds: quail, hen, 86 goose, and ostrich (Table 1). A comparison of their size and shape is given in Fig. 1A.

87

\section{Egg morphology and size}

In most nesting sites the titanosaur eggs are transformed, mostly compressed, during diagenesis; hence, it is difficult to assess exactly their original shape and diameter (Hechenleitner et al., 2016b). Therefore, we performed a CT-scan of a complete egg from Sanagasta (CRILAR-Pv 400 SA-C6-e1), using a 64-channel multi-slicer tomograph, at $140 \mathrm{Kv}$ and $403 \mathrm{~mA}$. The resulting CT dataset was analysed by using 3D Slicer v4.1.1 (Fedorov et al., 2012) and we obtained 141 three-dimensional structures that correspond to eggshell fragments. During the analysis of the CT we observed that the ellipsoidal shape of the egg CRILAR-Pv 400 SA-C6-e1 is a product of the displacement of shell fragments by the sediment. Using CAD software (DesignSpark Mechanical v.2015.0), we relocated each fragment to its original relative position (Fig. 1B). This produced an assembled model of spherical shape. Using this model we estimated the inner volume $\left(2500 \mathrm{~cm}^{3}\right)$ and inner diameter $(169 \mathrm{~mm})$, required to make the finite element model.

Size estimations of the eggs from Toteşti and Tama are based on CT data (Grellet-Tinner et al., 2012; Hechenleitner et al., 2016b). The estimations for the eggs from Boseong and Auca Mahuevo (Grellet-Tinner, Chiappe \& Coria, 2004; Hechenleitner, Grellet-Tinner \& Fiorelli, 2015) should be taken with caution until CT scans provide accurate data. All measurements are summarized in the Table 1.

\section{Eggshell mechanical properties}


107 biomechanical analyses must rely on data from living relatives. The titanosaur eggshells are homologous 108 to the internal-most layer (layer 1 or mammillary layer) of the bird's eggshell (Grellet-Tinner, Chiappe \& 109 Coria, 2004). Recent insightful information with respect to the mechanical properties of the eggs of 110 several living species of birds (Hahn et al., 2017) allow overcoming of the limitations imposed by 111 diagenesis for conducting finite element analyses (FEA) on titanosaur eggs. Input data for carrying out

112 FEA was obtained from the empirical tests performed on birds' eggshells (Hahn et al., 2017). We selected 113 average values from existing data (Table 1) for the calculations on titanosaur egg models. These are:

114 Young's modulus $(\mathrm{E})=17.51 \mathrm{GPa}$ and assumed a Poisson's ratio $(v)=0.3$.

115 The shell of the amniote egg has a tremendous structural complexity, including organic and 116 inorganic compounds (Board, 1982; Bain, 1991; Juang et al., 2017; Hahn et al., 2017) as well as voids

117 (e.g. pore canals and vesicles). Because data was obtained through empirical tests (Hahn et al., 2017), 118 measured mechanical properties result from the interaction of all of these variables. Hence, all the eggs 119 were modelled using a homogeneous "eggshell" material with the mechanical properties of a modern 120 bird's eggshell.

\section{Finite element models (FEM)}

The shape of the bird eggs varies considerably. As such, to construct the 3D egg models, we used

124 the outline of the eggs shown by Hahn et al., (2017) and assume each egg as a revolved solid. The

125 titanosaur eggs were modelled following the same protocol, although, based on previous data

126 (Hechenleitner et al., 2016b), we assumed a 2D circular outline. Thickness of the revolved solids in all

127 cases is equivalent to that of the respective eggshell. All models were made using CAD software (Fig. 128 1A).

129 To define the boundary conditions of the finite element models we located the centre of the egg in 130 the middle of its maximum-length axis (Fig. 1C). The external surface was fixed below $150^{\circ}$, to avoid 131 rotation of the models. 
In contrast to external resistance tests found in the literature (e.g. Juang et al., 2017; Hahn et al.,

133 2017), in which a force is applied on the apex of the eggs, we decided to apply the internal force in an

134 angle similar to that observed in birds during hatching. In modern birds the hatching point is variable,

135 between the equator and the blunt end of the egg. As such we selected a $30^{\circ}$ angle from the maximum-

136 length axis to apply the load force. The latter angle is only important for the asymmetric eggs, because the

137 shell does not mechanically behave uniformly.

138 In the present work we evaluate the structural response of the eggs to an internal force, emulating

139 the conditions of effort during hatching. Because the egg is a closed structure, it is impossible to do such

140 empirical tests without damaging the shell. In a recent paper, Juang et al. (2017) show that the eggs of all

141 avian species fractured from outside at a displacement to thickness ratio of about 1 . Because of its shape,

142 the structural behaviour of the egg is different from the internal and external side. However, although the

143 actual ratio may vary, the ratio $=1$ was used as a simplified criterion to determine the fracture force. This

144 means that we assumed that the shell breaks when the displacement at the load point equals its thickness.

145 As such, our model seeks to obtain a parameter in equivalent conditions among different eggs, which

146 allows comparison of the mechanical performance during hatching.

147 All models were meshed using tetrahedral elements of four nodes (see supplementary *.nas files),

148 considering that the eggshell material is isotropic and homogeneous. The elastic properties of each egg

149 model are specified in Table1. The finite element analyses were conducted using the software ADINA

$150 \quad \mathrm{v} 8.7 .3$.

151

152 Breaking force estimation

153 In all instances (birds and titanosaurs), we conducted exploratory analyses. Using internal forces of

154 different magnitude we recorded the eggshell displacement at the load point (Figs. 2A-2J; Table 2). Based

155 on these results, we estimated the inner load force required to obtain a displacement equal to the eggshell

156 thickness in each case (Fig. 3; Table 2).

157 


\section{Effect of the eggshell dissolution on the egg mechanical resistance}

In order to evaluate the effect of the dissolution of the eggshell in the Sanagasta eggs, as was previously hypothesized (Grellet-Tinner and Fiorelli, 2010; Grellet-Tinner et al., 2012b; Hechenleitner et al., 2016b), we generated and analysed models with different shell thicknesses between 7.9 and $1.2 \mathrm{~mm}$ (the maximum and minimum thicknesses recorded at this site). Each of these models was evaluated with an internal load force of $5 \mathrm{~N}$ (Figs. 4A-B). This magnitude corresponds to the average of forces previously estimated for all the titanosaur eggs in our sample, excluding the estimation for maximum thickness of the Sanagasta eggs. Based on the data of maximum displacement at the load point (Table 3), we estimated the maximum shell thickness that can be broken applying $5 \mathrm{~N}$.

\section{Statistical analysis}

We performed a multiple linear regression analysis to test the influence of the egg volume and shell thickness on the strength of the eggs (Fig. 5). To perform the statistical analysis we used the $1 \mathrm{~m}$ function from the package stats version 3.4.3 of the open source software R (R CoreTeam, 2017).

Two models were performed in order to evaluate the relationship between variables; one model with interaction of the variables volume and thickness and one without interaction. The AIC method was used to select the model that better fits to data. A residual vs. leverage plot of the fittest model helped to identify extreme values within the data set.

\section{RESULTS}

According to the present 3D reconstruction, the Sanagasta eggs were originally spherical (Fig. 1B). This is consistent and supports all previous publications on titanosaur eggs (Grellet-Tinner, Chiappe \& Coria, 2004; Grellet-Tinner, Fiorelli \& Salvador, 2012; Hechenleitner, Grellet-Tinner \& Fiorelli, 2015). Furthermore, the present CT-scan-based analysis shows that previous studies overestimated the size of these eggs (Fig. 1B). After digitally rearranging the eggshell fragments, the external egg diameter decreased from $\sim 210 \mathrm{~mm}\left(\sim 4850 \mathrm{~cm}^{3}\right.$ in volume $)$ to $\sim 180 \mathrm{~mm}\left(\sim 3370 \mathrm{~cm}^{3}\right)$. Such a reduction in volume 
184 involves much less internal space for nutrient storage and embryo development. In addition, the diameter

185 of the embryonic chamber of the Sanagasta eggs only reaches $169.2 \mathrm{~mm}$ due to the considerable shell

186 thickness of these eggs (Fig. 1B). Therefore, although the Sanagasta eggs are larger than those of Tama, a

187 nesting site found less than $150 \mathrm{~km}$ away in the same stratigraphic unit (Hechenleitner et al., 2016b), both

188 display an identical chamber space available for the developing embryo (Table 1).

189 The 3D FEA conducted here, which are the first of their kind, allowed estimations that an effort of 190 3.04-9.77 N could break most of the titanosaur egg samples, namely Tama, Toteşti, Boseong, and Auca

191 Mahuevo (Figs. 2A-F and 3). In contrast, the eggs of Sanagasta are 14-45 times stronger, requiring up to $192136 \mathrm{~N}$ to break.

193 Porosity could affect the eggshell's strength, although to date, there is no quantitative information

194 in this regard (Hahn et al., 2017). Eggshell strength in modern birds has been correlated with several

195 factors, e.g. calcium diet, shell microstructure, incubation period; however, shell thickness is the main

196 factor affecting strength (Ar, Rahn \& Paganelli, 1979). The statistical model corroborated that there is an

197 important linear association between egg internal volume and shell thickness $\left(F_{(1,8)}=16.93, R^{2}=0.64, p=\right.$

$1983.40^{-4}$ ), although an over-dispersion of thickness values becomes evident as volume increases (Fig. 5A).

199 From the two multiple linear regression models tested, the model that better explains the relationship

200 between internal volume and eggshell thickness as independent variables, and the shell mechanical

201 strength as response variable was the model without interaction $(\mathrm{AIC}=14.13)$. The regression analysis

202 showed a statistical association between eggshell thickness and the mechanical strength of the eggs

$203\left(\mathrm{~F}_{(2,7)}=107.1, \mathrm{R}^{2}=0.96, \mathrm{p}=8.53^{-5}\right.$; Fig. $\left.5 \mathrm{~B}\right)$, whereas there is not a direct association with egg internal

204 volume $\left(\mathrm{F}_{(2,7)}=107.1, \mathrm{R}^{2}=0.96, \mathrm{p}=0.80\right.$; Fig. 5C). The residual $v$ s leverage plot shows that the thick-

205 shelled egg from Sanagasta and the quail egg represent outlier values, and according to the Cook's

206 distance, they are strong influential observations for the model (Fig. 5D).

207 Considering that the geological and palaeontological data, as well as the evidence from modern

208 analogues, suggest that the eggshells of Sanagasta would have partially dissolved during incubation, we

209 further tested the mechanical effect of their constant thinning (Figs. 4A-B; Table 3). Results indicate that 
210 the average estimate for the other titanosaur eggs $(5 \mathrm{~N})$, has little effect on the Sanagasta egg, when its

211 shell is thick (Figs. 4A-B). However, as the thinning progresses, the shell strength drops abruptly. When

212 thinning reaches $\sim 1.6 \mathrm{~mm}$, the shell reaches its fracture threshold and, as previously speculated (Grellet-

213 Tinner, Fiorelli \& Salvador, 2012; Hechenleitner et al., 2016a), it breaks easily at and below this

214 threshold (Figs. 4A-B).

215

216

217

218

219

220

221

222

223

224

225

226

227

228

229

230

231

232

233

234

\section{DISCUSSION}

The concept that all of the eggs of titanosaurs are spherical is well established. However, several sites preserve deformed and/or incomplete eggs (Huh \& Zelenitsky, 2002; Salgado et al., 2009; Jackson, Schmitt \& Oser, 2013; Hechenleitner et al., 2016b), and there is little CT information available to reconstruct their original shape and volume. The CT scan of the specimen CRILAR-Pv 400 SA-C6-e1 confirmed that the Sanagasta eggs were spherical. A spherical shape in eggs is mechanically and physiologically optimal. It has a greater resistance to impacts and is the smallest surface with respect to any geometric figure of equal volume (Bain, 1991; Stoddard et al., 2017). As such it is advantageous in terms of strength, shell economy, and heat conservation (Kratochvil \& Frynta, 2006; Stoddard et al., 2017).

Currently, there is strong evidence for titanosaurs' precociality or hyperprecociality (Hechenleitner, Grellet-Tinner \& Fiorelli, 2015; Curry Rogers et al., 2016). Precociality requires a relatively greater amount of available nutrients and therefore a larger egg size. Egg internal diameter constitutes a valuable proxy for the size of a fully developed embryo, so its precise measurement is important to figure out how big (and, eventually estimate, how strong) the embryo could have been. The new data shows that the Sanagasta and Tama eggs have nearly the same internal space for accommodating an embryo. This suggests that the hatchlings of Sanagasta could have been strong enough to pip through (at least) a 1.5 mm-thick eggshell (Table 1). However, hatching through a $7.9 \mathrm{~mm}$-thick shell, more than three times thicker than other titanosaur eggs (depending on which species), seems unlikely. 

factors (Board, 1982). They must be strong enough to prevent fracture, but sufficiently weak to allow

237 hatching. This relationship is corroborated by the statistical analysis of the present data, which shows an 238 association between the eggshell thickness and strength of the eggs $\left(\mathrm{F}_{(2,7)}=107.1, \mathrm{R}^{2}=0.96, \mathrm{p}=8.53^{-5}\right.$; Fig.

239 5B). The titanosaur eggs show, in general, a good fit to the statistical model (Fig. 5C). However, the

240 Sanagasta eggs with thick shell fall entirely outside these predictions. According to the FEA, they were

241 14-45 times stronger than any other titanosaur eggs that have nearly the same space for accommodating a

242 late term embryo, such as those of Tama and Boseong. Thus, the Sanagasta embryos would have had to

243 invest a considerable amount of energy to be able to hatch, if the eggs kept their thickness constant during

244 the whole incubation.

Recapitulating on the adaptive advantage of such a thick shell for the Sanagasta specimens, two reasons that are not mutually exclusive can be considered: mechanical strength and resistance to chemical abrasion. Most titanosaurs laid biologically and mechanically viable eggs with thinner shells (e.g. Auca Mahuevo, Toteşti), which rarely exceed $2 \mathrm{~mm}$, thus suggesting that strength was not a primary reason for developing thick eggshells. This shows that the excessive thickness of the Sanagasta shells would not respond to a mechanical need (e.g. withstand shock from outside). consequences for the Sanagasta titanosaurs. First, it would be detrimental for the development of the embryo because, as it grows, its needs change from preventing water loss to increasing gas exchange, due to the increase in energy consumption of a late embryo [a process documented among mound-nester archosaurs (Ferguson, 1981; Booth \& Seymour, 1987; Hechenleitner et al., 2016a)]. Second, a very thick eggshell might also represent a problem during hatching, as is suggested by the new results (Fig. 2A and

257 Fig. 3). The case was pointed out by empirically studying Alligator mississippiensis, which bury their

258 eggs in mounds of vegetation, in a way similar to that used by some titanosaurs and megapode birds

259 (Hechenleitner, Grellet-Tinner \& Fiorelli, 2015). Eggs incubated artificially (without natural substrate)

260 develop normally, but then, the fully grown embryos are unable to break their shell (Ferguson, 1981). In 
261 nature, the dissolution of the A. mississippiensis eggshell is mediated by bacterial decomposition, which

262 acidifies the nesting environment. Given the environmental similarities for ground-nesting, it is not

263 surprising that the shells of several titanosaur nesting sites show evidence of extrinsic dissolution

264 (Grellet-Tinner, Chiappe \& Coria, 2004; Hechenleitner, Grellet-Tinner \& Fiorelli, 2015). This type of

265 dissolution should not be confused with the internal calcium absorption produced in the late stages of the

266 embryogenesis, which is ubiquitous among archosaurs (Chien, Hincke \& McKee, 2009). During

267 ossification the calcium is removed from the shell, getting to reduce up to $20 \%$ of its thickness in

268 precocial birds, such as the megapodes (Booth \& Seymour, 1987). However, these high values are

269 associated with very thin eggshells, in which the removal mostly affects the base of the structural units of

270 calcite, in the innermost portion of the shell. Indeed, some internal dissolution in the Sanagasta eggshells

271 was related with calcium resorption, but is negligible compared to the shell's thickness (Grellet-Tinner,

272 Fiorelli \& Salvador, 2012).

273 The results of FEA conducted on models of Sanagasta eggs with different shell thicknesses,

274 between the minimum and maximum shell thickness reported for this site, show that an effort similar to

275 the one necessary to break other titanosaur eggs would have had very little effect on those of Sanagasta

276 immediately after oviposition (Figs. 4A-B). However, when the thickness is reduced to less than $1.6 \mathrm{~mm}$,

277 the shell becomes as fragile as for other titanosaur eggs.

278 The nesting strategies of titanosaurs have been compared with those of modern megapodes

279 (Kerourio, 1981; Cousin \& Breton, 2000; Garcia et al., 2008; Grellet-Tinner \& Fiorelli, 2010; Grellet-

280 Tinner, Fiorelli \& Salvador, 2012; Hechenleitner, Grellet-Tinner \& Fiorelli, 2015; Grellet-Tinner,

281 Lindsay \& Thompson, 2017). To date, only a handful of dinosaur species are confirmed to exploit and

282 have exploited the geothermalism as a source of heat for incubating their eggs (Jones \& Birks, 1992;

283 Grellet-Tinner \& Fiorelli, 2010; Harris, Birks \& Leaché, 2014; Hechenleitner, Grellet-Tinner \& Fiorelli,

284 2015; Grellet-Tinner, Lindsay \& Thompson, 2017). The eggshell structure of modern dinosaurs differ

285 from those of their ancestors by having three to four structural layers that confer a greater strength for a

286 thinner eggshell thickness (Grellet-Tinner, 2006), instead of one structural layer like the Sanagasta 
287 dinosaur eggs. Macrocephalon maleo and Megapodius pritchardii are two modern megapode species that

288 resort or revert to geothermal incubation, although the former, in Sulawesi Island, have two populations

289 that do not interbreed and respectively utilize black sand with solar radiation and geothermal heated sand.

290 However, the latter do oviposit in sands heated by in geothermal activities and M. pritchardii in the

291 volcanic ashes of calderas. In both instances the megapode eggs are not in direct contact with geothermal

292 fluids. Leipoa ocellata and Alectura lathami, two mound-builder megapodes that inhabit Australia, must

293 also deal with the risks of external acidic erosion. In their mound-nests the activity of microorganisms

294 that maintains a high incubation temperature (Seymour \& Ackerman, 1980) also produces organic acids

295 as a by-product (Grellet-Tinner, Lindsay \& Thompson, 2017). The eggshells of both species have an

296 accessory layer composed of nanospheres of calcium phosphate on their outer surface (Board, 1980).

297 D'Alba et al. (2014) showed that this accessory layer has antimicrobial properties. In addition, the calcium

298 phosphate of the nanospheres is, compared to the calcite present in the structural layers of the eggshell, a

299 relatively insoluble salt (Board, 1980). For this reason it has been recently suggested that the accessory

300 layer also constitutes a protective cover that prevents the external erosion of the shell (Grellet-Tinner,

301 Lindsay \& Thompson, 2017). In addition, the pronounced nodular surficial ornamentation of these eggs

302 complements the calcium phosphate nanospheres against chemical erosion by limiting most of the

303 external erosion of their eggshell to these nodes. Therefore, although a few species of modern megapodes

304 may display a reversal that utilizes ground generated heat as a passive incubating energy, their incubating

305 strategies differ from the Sanagasta dinosaurs, which eggs were in direct contact with acidic geothermal

306 fluids (Grellet-Tinner \& Fiorelli, 2010).

307

308 CONCLUSIONS

309 The FEA data suggest that hatching through a $7.9 \mathrm{~mm}$ thick shell was impossible for the embryos

310 from Sanagasta. However, the analyses carried out on egg models with different shell thicknesses further

311 suggest that thinning below $2 \mathrm{~mm}$ would have allowed these titanosaurs to hatch. With regard to the

312 relationship between eggshell thickness and egg strength, the thick-shelled Sanagasta eggs are completely 
313 out of the prediction of the statistical model. In other words, the model shows that in terms of the

314 strength/thickness ratio, the Sanagasta eggshells are disproportionately thick with respect to those

315 recorded for birds and other titanosaurs. As the original thickness would have been a strong limitation for

316 hatching, the present results are consistent with previous arguments of outer eggshell thinning in the

317 Sanagasta nesting site (Grellet-Tinner \& Fiorelli, 2010; Grellet-Tinner, Fiorelli \& Salvador, 2012).

318 Considering that titanosaur eggs were incubated in fairly acid nesting environments, such as mounds or

319 dug-out holes as seen in the modern megapodes (Hechenleitner, Grellet-Tinner \& Fiorelli, 2015), it is

320 plausible that the force required for hatching would be even less than estimated. Regardless of the factors

321 (intrinsic and/or extrinsic) involved in the wear of $\sim 80 \%$ of the eggshell, our results strongly suggest that

322 external chemical dissolution, here complemented by the typical internal ontogenetic dissolution,

323 throughout the incubation process would have been essential for allowing hatching of the titanosaurs that

324 nested at Sanagasta.

325

326 ACKNOWLEDGEMENTS

327 We thank the Secretaría de Cultura and Gobierno de La Rioja, Municipalidad de Tama and Sanagasta for 328 their help and support.

329

\section{REFERENCES}

331 Ar A., Rahn H., Paganelli C V. 1979. The avian egg: Mass and strength. Condor 81:331-337.

332 Bain MM. 1991. Eggshell strength: A relationship between the mechanism of failure and the

333 ultrastructural organisation of the mammillary layer. British Poultry Science 33:303-319.

334 Board RG. 1980. The avian eggshell—a resistance network. Journal of Applied Bacteriology 48:303-313.

335 Board RG. 1982. Properties of avian egg shells and their adaptive value. Biological Reviews 57:1-28.

336 Booth DT., Seymour RS. 1987. Effect of eggshell thinning on water vapor conductance of malleefowl

337 eggs. The Condor 89:453-459.

338 Chien YC., Hincke MT., McKee MD. 2009. Ultrastructure of avian eggshell during resorption following 
egg fertilization. Journal of Structural Biology 168:527-538.

Cousin R., Breton G. 2000. A precise and complete excavation is necessary to demonstrate a dinosaur clutch structure. In: First International Symposium on dinosaur eggs and babies/Extended abstracts. $31-42$.

Curry Rogers K., Whitney M., D’Emic M., Bagley B. 2016. Precocity in a tiny titanosaur from the Cretaceous of Madagascar. Science 352:450-453.

D’Alba L., Jones DN., Badawy HT., Eliason CM., Shawkey MD. 2014. Antimicrobial properties of a nanostructured eggshell from a compost-nesting bird. The Journal of Experimental Biology 217:1116-21.

Eagle RA., Enriquez M., Grellet-Tinner G., Pérez-Huerta A., Hu D., Tütken T., Montanari S., Loyd SJ., Ramirez P., Tripati AK., Kohn MJ., Cerling TE., Chiappe LM., Eiler JM. 2015. Isotopic ordering in eggshells reflects body temperatures and suggests differing thermophysiology in two Cretaceous dinosaurs. Nature Communications 6:8296.

Fedorov A., Beichel R., Kalpathy-Cramer J., Finet J., Fillion-Robin JC., Pujol S., Bauer C., Jennings D., Fennessy F., Sonka M., Buatti J., Aylward S., Miller J V., Pieper S., Kikinis R. 2012. 3D Slicer as an image computing platform for the Quantitative Imaging Network. Magnetic Resonance Imaging 30:1323-1341.

Ferguson MWJ. 1981. Extrinsic microbial degradation of the alligator eggshell. Science 214:1135-1137.

Fiorelli LE., Grellet-Tinner G., Alasino PH., Argañaraz E. 2012. The geology and palaeoecology of the newly discovered Cretaceous neosauropod hydrothermal nesting site in Sanagasta (Los Llanos Formation), La Rioja, northwest Argentina. Cretaceous Research 35, 94-117.

Garcia G., Khosla A., Jafar SA., Sahni A., AVianey-Liaud M. 2008. Eggshell microstructure and porosity of the Nicobar scrubfowl (Megapodius nicobarensism, Great Nicobar Island, India). Palaeovertebrata 36:75-87.

García RA. 2007. An "egg-tooth"-like structure in titanosaurian sauropod embryos. Journal of Vertebrate Paleontology 27(1):247-252. 
365

366

367

368

369

370

371

372

373

374

375

376

377

378

379

380

381

382

383

384

Göth A., Vogel U. 1997. Egg laying and incubation of Polynesian megapode. Annual Review of the World Pheasant Association 1996/97:43-54.

Grellet-Tinner G. 2006. Phylogenetic interpretation of eggs and eggshells: implications for phylogeny of Palaeognathae. Alcheringa 30:141-182.

Grellet-Tinner G., Codrea V., Folie A., Higa A., Smith T. 2012. First evidence of reproductive adaptation to "island effect" of a dwarf Cretaceous Romanian titanosaur, with embryonic integument in ovo. PloS One 7:e32051.

Grellet-Tinner G., Chiappe LM., Coria RA. 2004. Eggs of titanosaurid sauropods from the Upper Cretaceous of Auca Mahuevo (Argentina). Canadian Journal of Earth Sciences 41:949-960.

Grellet-Tinner G., Fiorelli LE. 2010. A new Argentinean nesting site showing neosauropod dinosaur reproduction in a Cretaceous hydrothermal environment. Nature Communications 1:32.

Grellet-Tinner G., Fiorelli LE., Salvador RB. 2012. Water vapor conductance of the Lower Cretaceous dinosaurian eggs from Sanagasta, La Rioja, Argentina: Paleobiological and paleoecological implications for South American faveoloolithid and megaloolithid eggs. Palaios 27:35-47.

Grellet-Tinner G., Lindsay S., Thompson MB. 2017. The biomechanical, chemical and physiological adaptations of the eggs of two Australian megapodes to their nesting strategies and their implications for extinct titanosaur dinosaurs. Journal of Microscopy 267:237-249.

Guo P., Liu SY., Feng JC., He M. 2008. The description of a new species of Thermophis (Serpentes: Colubridae). Sichuan Journal of Zoology 27:321.

Hahn EN., Sherman VR., Pissarenko A., Rohrbach SD., Fernandes DJ., Meyers MA. 2017. Nature's technical ceramic: the avian eggshell. Journal of The Royal Society Interface 14:20160804.

Harris RB., Birks SM., Leaché AD. 2014. Incubator birds: biogeographical origins and evolution of underground nesting in megapodes (Galliformes: Megapodiidae). Journal of Biogeography 41:2045-2056.

Hechenleitner EM., Grellet-Tinner G., Foley M., Fiorelli LE., Thompson MB. 2016a. Micro-CT scan reveals an unexpected high-volume and interconnected pore network in a Cretaceous Sanagasta 
dinosaur eggshell. Journal of The Royal Society Interface 13:20160008.

392 Hechenleitner EM., Fiorelli LE., Grellet-Tinner G., Leuzinger L., Basilici G., Taborda JRA., de la Vega

393 SR., Bustamante CA. 2016b. A new Upper Cretaceous titanosaur nesting site from La Rioja (NW

394 Argentina), with implications for titanosaur nesting strategies. Palaeontology 59:433-446.

Hechenleitner EM., Grellet-Tinner G., Fiorelli LE. 2015. What do giant titanosaur dinosaurs and modern Australasian megapodes have in common? PeerJ 3:e1341.

Hermyt M., Kaczmarek P., Kowalska M., Rupik W. 2017. Development of the egg tooth - The tool facilitating hatching of squamates: Lessons from the grass snake Natrix natrix. Zoologischer Anzeiger 266:61-70.

Hieronymus TL., Witmer LM. 2010. Homology and Evolution of Avian Compound Rhamphothecae. The Auk 127:590-604.

Honza M., Picman J., Grim T., Novák V., Čapek JM., Mrlík V. 2001. How to hatch from an egg of great structural strength. A study of the Common Cuckoo. Journal of Avian Biology 32:249-255.

Huh M., Zelenitsky DK. 2002. Rich dinosaur nesting site from the Creataceous of Bosung County, Chullanam-Do Province, South Korea. Journal of Vertebrate Paleontology 22:716-718.

Jackson FD., Schmitt JG., Oser SE. 2013. Influence of vertisol development on sauropod egg taphonomy and distribution at the Auca Mahuevo locality, Patagonia, Argentina. Palaeogeography, Palaeoclimatology, Palaeoecology 386:300-307.

Jones D., Birks S. 1992. Megapodes: recent ideas on origins, adaptations and reproduction. Trends in Ecology and Evolution 7:88-91.

Juang JY., Chen PY., Yang DC., Wu SP., Yen A., Hsieh HI. 2017. The avian egg exhibits general allometric invariances in mechanical design. Scientific Reports 7:1-11.

Kerourio P. 1981. Nouvelles observations sur le mode de nidification et de ponte chez les dinosauriens du Crétacé terminal du Midi de la France. Compte rendu sommatre des sélances de la Sociéité Géologique de France 1:25-28.

Kratochvil L., Frynta D. 2006. Egg shape and size allometry in geckos (Squamata: Gekkota), lizards with 

Evolutionary Research 44:217-222.

R CoreTeam. 2017. R: A language and environment for statistical computing.

Salgado L., Magalhães Ribeiro C., García RA., Fernández MS. 2009. Late Cretaceous Megaloolithid eggs

Seymour RS. 2013. Maximal aerobic and anaerobic power generation in large crocodiles versus mammals: implications for dinosaur gigantothermy. PloS One 8:e69361.

Seymour RS., Ackerman RA. 1980. Adaptations to underground nesting in birds and reptiles. American Zoologist 20:437-447.

Stoddard MC., Yong EH., Akkaynak D., Sheard C., Tobias JA., Mahadevan L. 2017. Avian egg shape: Form, function, and evolution. Science 356:1249-1254.

Werner DI. 1983. Reproduction in the Iguana Conolophus subcristatus on Fernandina Island, Galapagos: Clutch Size and Migration Costs. The American Naturalist 121:757-775.

Werner J., Griebeler EM. 2014. Allometries of maximum growth rate versus body mass at maximum growth indicate that non-avian dinosaurs had growth rates typical of fast growing ectothermic sauropsids. PloS one 9:e88834.

\section{FIGURES}

Figure 1. Dinosaur eggs. (A) Schematic silhouettes of the titanosaur and modern bird eggs used in the 
443 mechanical analyses. (B) Reconstruction of CRILAR-Pv 400 SA-C6-e1. (C) Boundary conditions for the 444 analyses. Abbreviation: F, inner load force.

445

Figure 2. Break point estimations for each egg model. (A) Sanagasta eggs with the thickest shell

447 reported for this site. (B) Sanagasta eggs with the thinnest shell reported for this site. (C) Tama. (D) Auca 448 Mahuevo. (E) Boseong. (F) Toteşti. (G) Ostrich. (H) Goose. (I) Hen. (J) Quail. Blue dots, FEA results for 449 each test. Red dot, break point estimated by the regression. Results are given in Table 2.

450

451

Figure 3. Egg strength of several dinosaur eggs. Fracture limit of each egg as a function of its shell 452 thickness.

453

Figure 4. Strength variations of the Sanagasta eggs. (A) Strength variations as incubation progresses,

455

456

457

458

459

460

461

462

463

464

465

466

467

according to Grellet-Tinner \& Fiorelli (2010). (B) Detail of strength variation for the Sanagasta eggs as thinning progresses. Note that displacement equals shell thickness when dissolution reaches $\sim 6.3 \mathrm{~mm}$ $($ shell thickness $=\sim 1.6 \mathrm{~mm})$

Figure 5. Statistical analysis. Multiple linear regression between: (A) Egg volume and shell thickness, (B) egg thickness and strength, and (C) egg volume and strength. (D) Model diagnostic plot of standardized residuals vs. leverage, showing the most extreme and influencing thickness values on the eggshell strength, corresponding to the thick shelled eggs from Sanagasta (2) and the quail eggs (10). Red and blue dots correspond to titanosaur and avian eggs respectively. Reference numbers: (1) Sanagasta (thick); (2) Sanagasta (thin); (3) Tama; (4) Auca Mahuevo; (5) Boseong; (6) Toteşti; (7) Ostrich; (8) Goose; (9) Hen; (10) Quail.

\section{TABLES}


468 Table 1. Avian and non-avian dinosaur eggs used in the comparative analyses. Specifications for

469 each egg model. d, inner diameter. E, Young's modulus (for all titanosaur models this value is 17.51

$470 \mathrm{GPa}) \mathrm{V}$, inner volume. X1, X2, X3, spatial coordinates of the load point.

471

472 Table 2. Summary of the breaking force tests for each egg model. BP, break point estimated by

473 regression. D, maximum displacement at the load point. F, inner load force. T\#, test number.

474

475 Table 3. Results of FEA on Sanagasta egg models with different eggshell thicknesses. 
Figure 1

Dinosaur eggs.

(A) Schematic silhouettes of the titanosaur and modern bird eggs used in the mechanical analyses. (B) Reconstruction of CRILAR-Pv 400 SA-C6-e1. (C) Boundary conditions for the analyses. Abbreviation: $F$, inner load force.

A

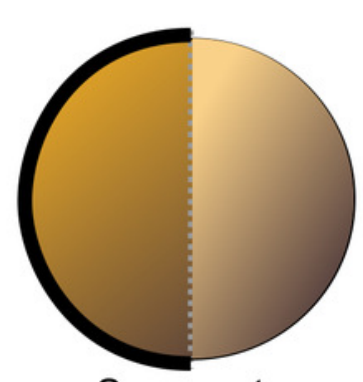

Sanagasta

(thick/thin eggshell)

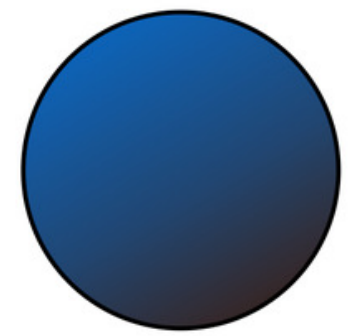

Tama

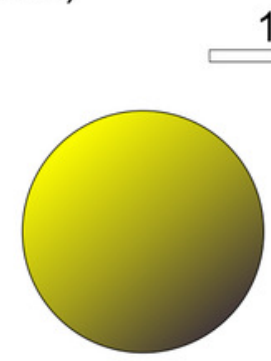

Auca Mahuevo

Toteşti

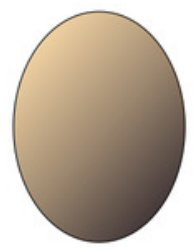

Ostrich

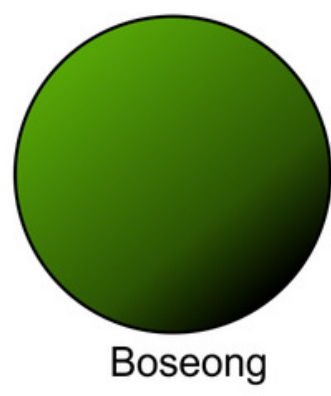

C
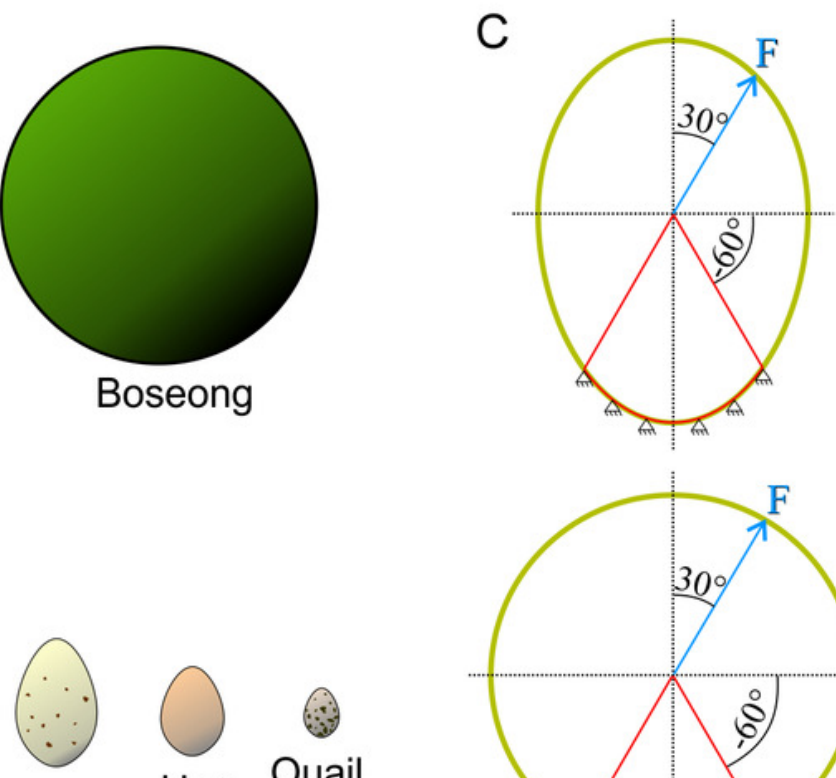

Goose

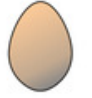

Hen

Quail
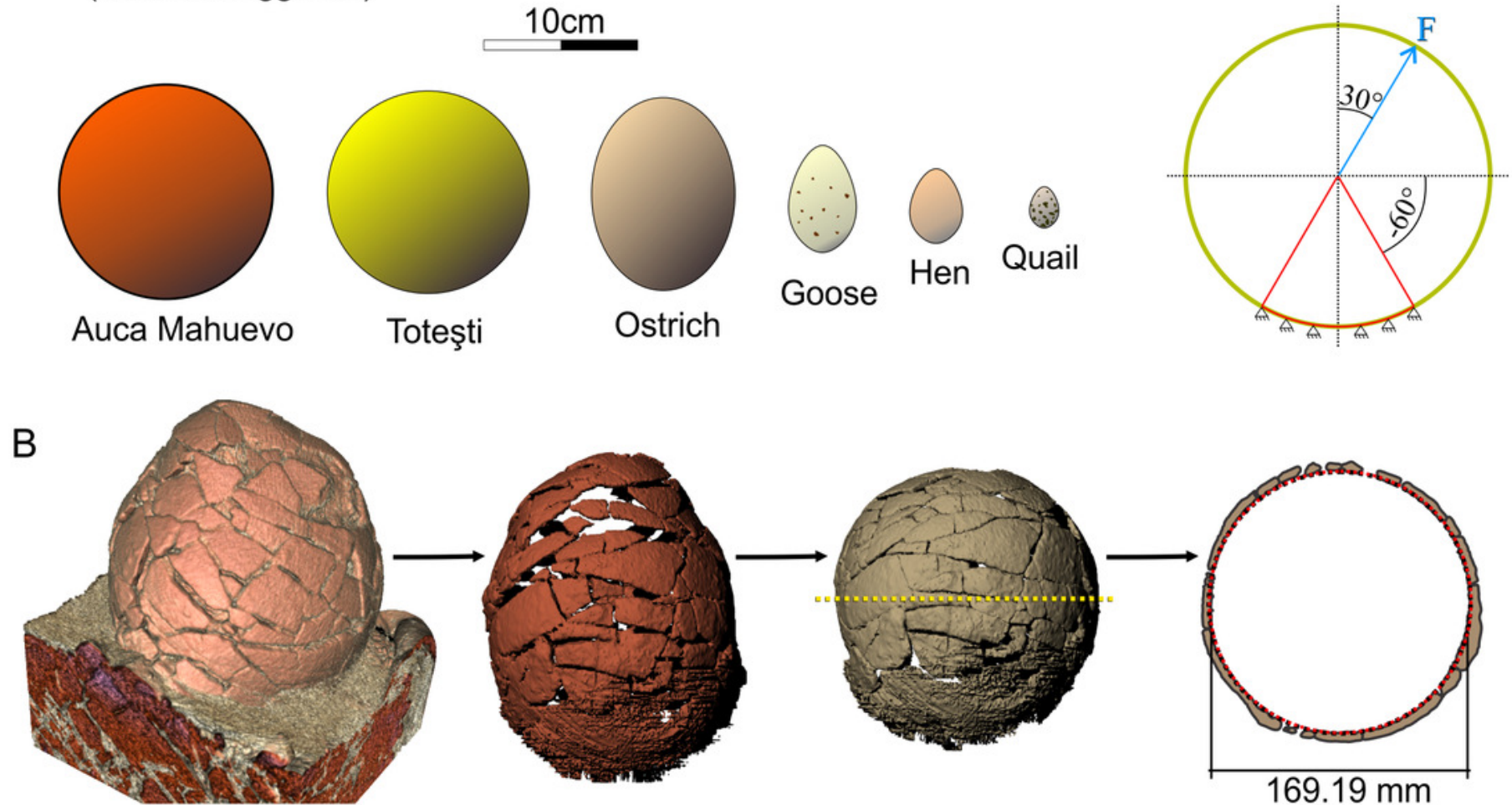
Figure 2

Break point estimations for each egg model.

(A) Sanagasta eggs with the thickest shell reported for this site. (B) Sanagasta eggs with the thinnest shell reported for this site. (C) Tama. (D) Auca Mahuevo. (E) Boseong. (F) Toteşti. (G) Ostrich. (H) Goose. (I) Hen. (J) Quail. Blue dots, FEA results for each test. Red dot, break point estimated by the regression. Results are given in Table 2 .
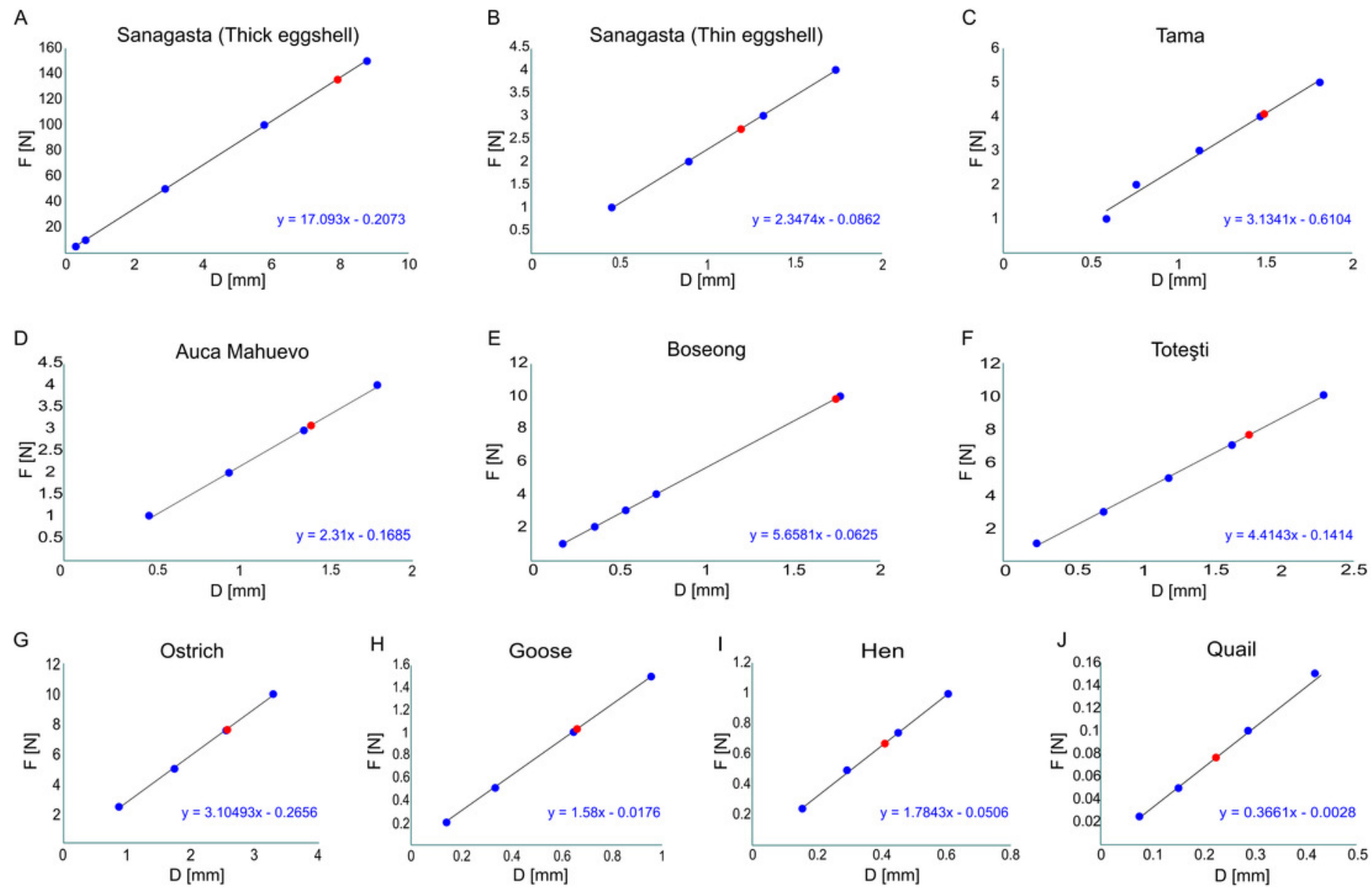
Figure 3

Egg strength of several dinosaur eggs.

Fracture limit of each egg as a function of its shell thickness.

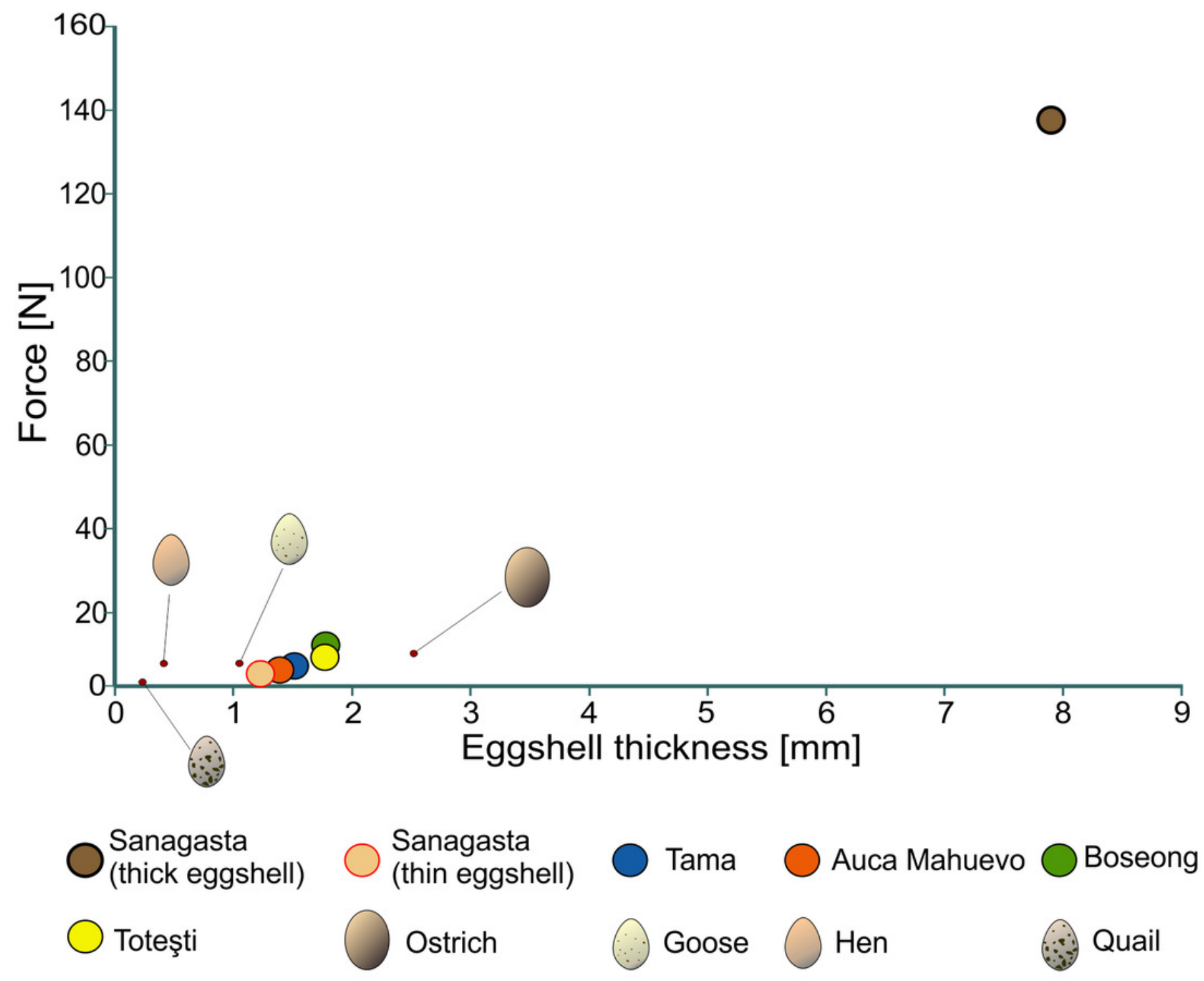




\section{Figure 4}

Strength variations of the Sanagasta eggs.

(A) Strength variations as incubation progresses, according to Grellet-Tinner \& Fiorelli (2010).

(B) Detail of strength variation for the Sanagasta eggs as thinning progresses. Note that displacement equals shell thickness when dissolution reaches $\sim 6.3 \mathrm{~mm}$ (shell thickness $=$ $\sim 1.6 \mathrm{~mm}$ ) 


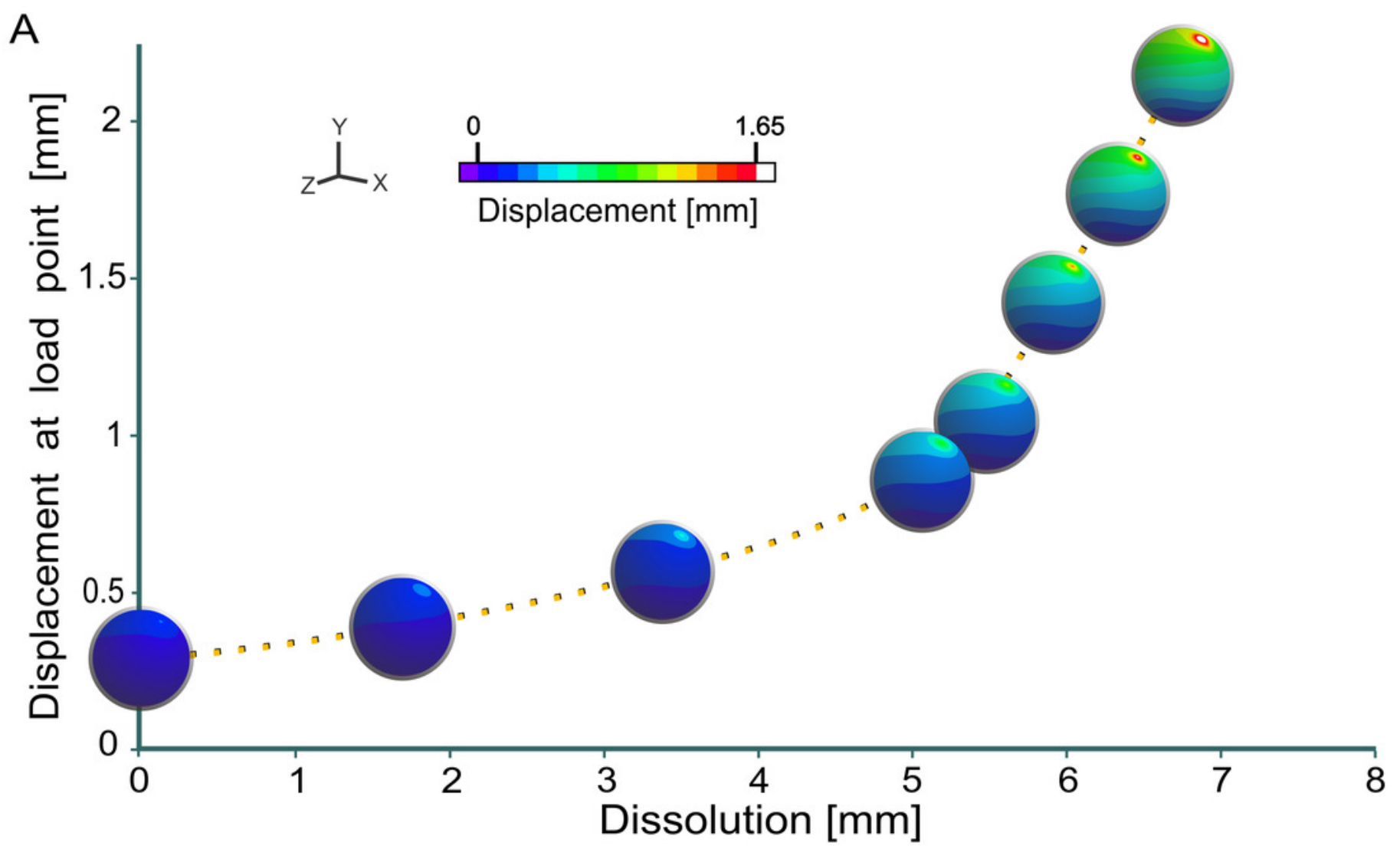

B
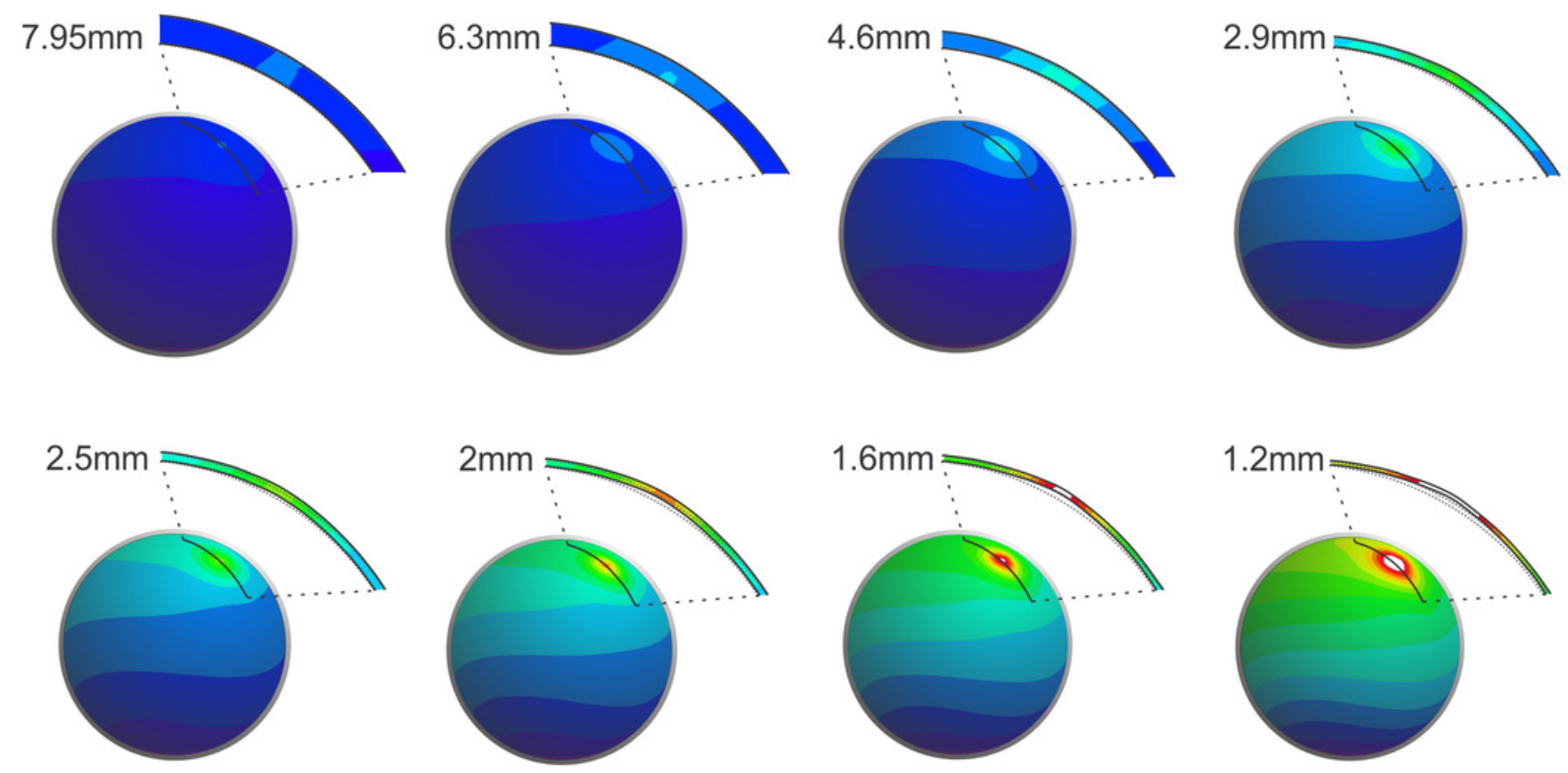

$\stackrel{Y}{Z}_{X}^{Y}$

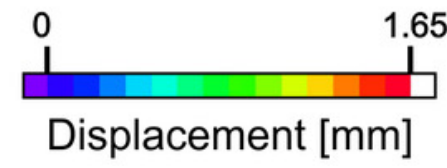




\section{Figure 5}

Statistical analysis.

Multiple linear regression between: (A) Egg volume and shell thickness, (B) egg thickness and strength, and (C) egg volume and strength. (D) Model diagnostic plot of standardized residuals vs. leverage, showing the most extreme and influencing thickness values on the eggshell strength, corresponding to the thick shelled eggs from Sanagasta (2) and the quail eggs (10). Red and blue dots correspond to titanosaur and avian eggs respectively. Reference numbers: (1) Sanagasta (thick); (2) Sanagasta (thin); (3) Tama; (4) Auca Mahuevo; (5) Boseong; (6) Toteşti; (7) Ostrich; (8) Goose; (9) Hen; (10) Quail. 

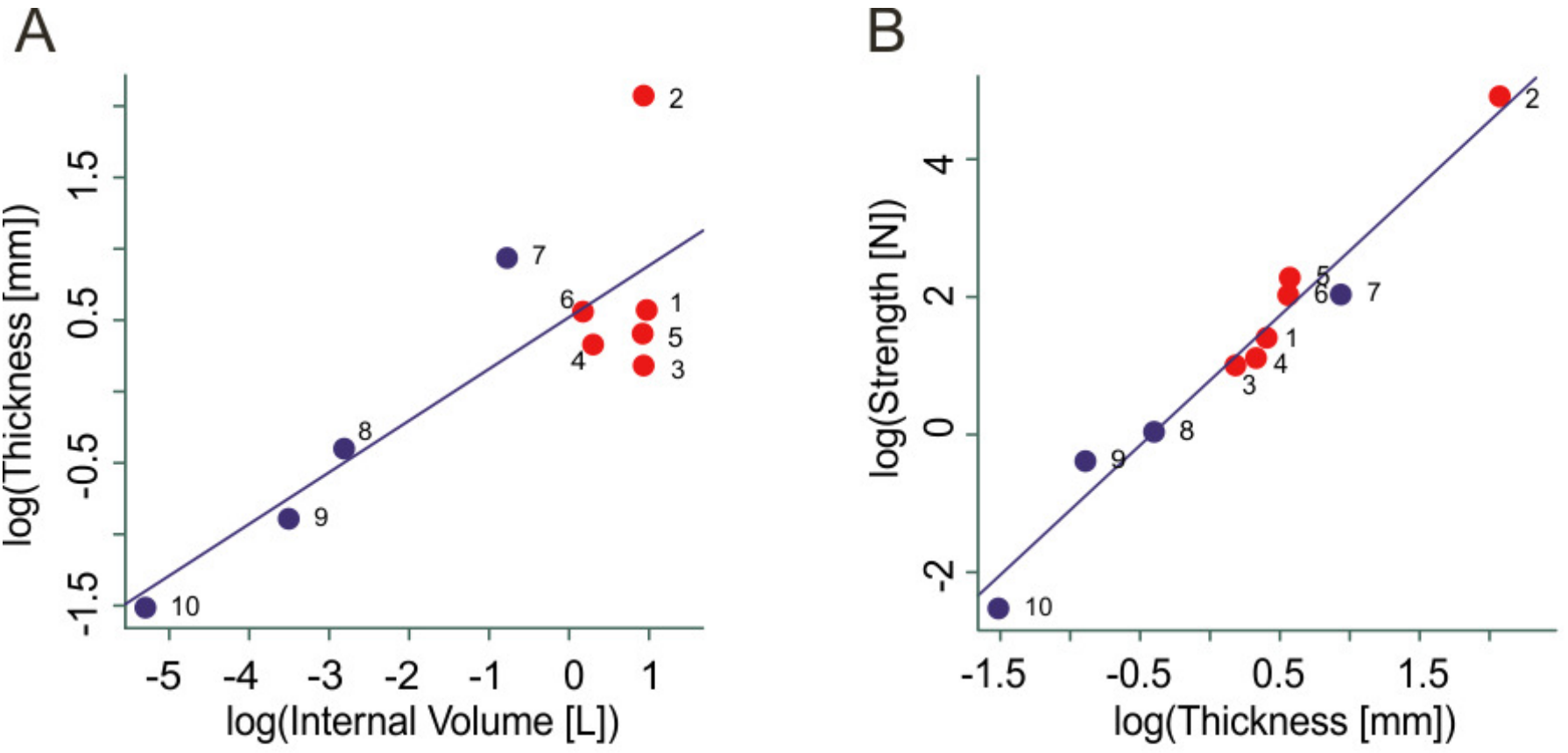

C

D
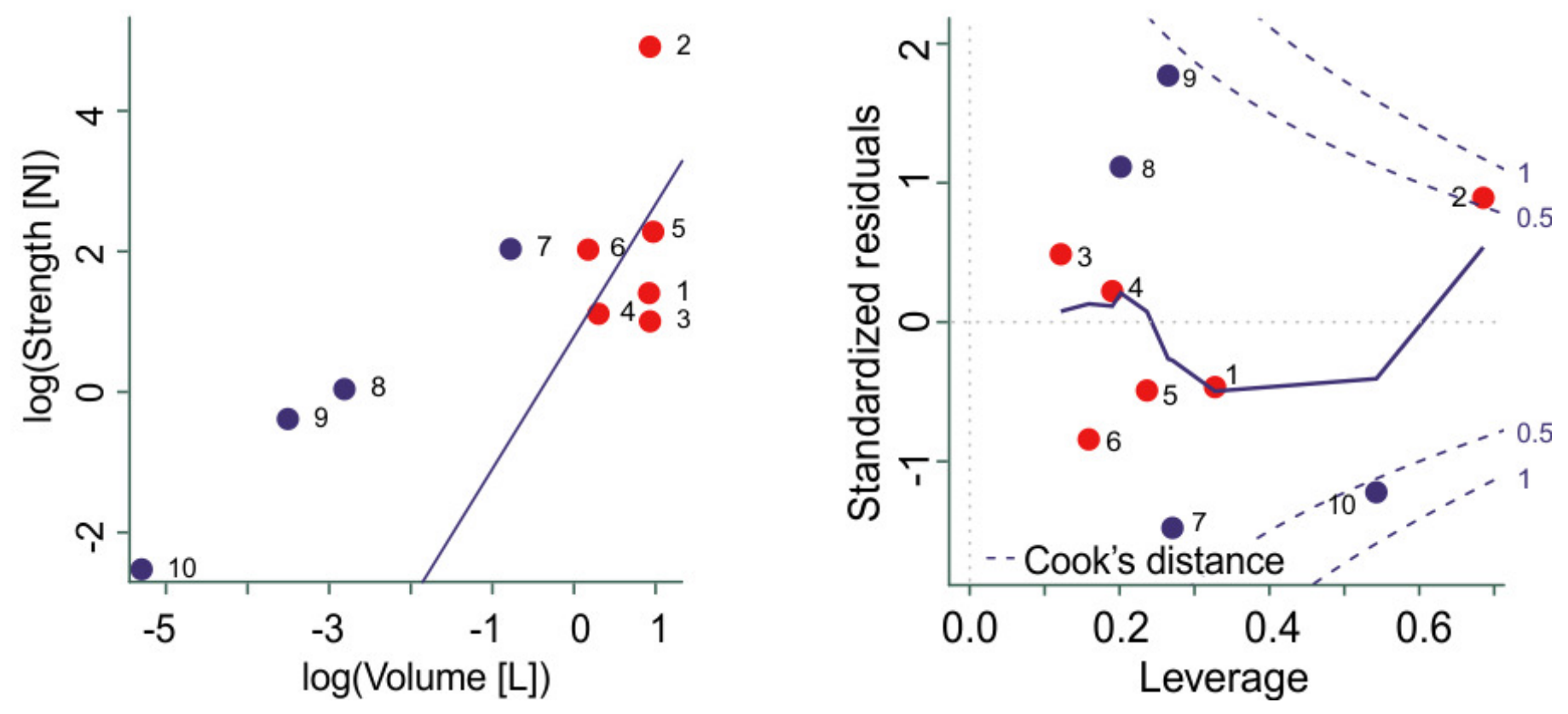


\section{Table $\mathbf{1}$ (on next page)}

Avian and non-avian dinosaur eggs used in the comparative analyses.

Specifications for each egg model. $d$, inner diameter. E, Young's modulus (for all titanosaur models this value is $17.51 \mathrm{GPa}$ ). $\mathrm{V}$, inner volume. $\mathrm{X} 1, \mathrm{X} 2, \mathrm{X} 3$, spatial coordinates of the load point. 


\begin{tabular}{|c|c|c|c|c|c|c|c|}
\hline \multirow{2}{*}{ Living Birds } & \multirow{2}{*}{$\begin{array}{c}\text { Thickness } \\
\text { [mm] }\end{array}$} & \multirow{2}{*}{$\mathbf{V}[\mathbf{L}]$} & \multirow{2}{*}{ E [Gpa] } & \multicolumn{3}{|c|}{ Load point } & \multirow{2}{*}{ Source } \\
\hline & & & & $\mathbf{X} 1$ & $\mathrm{X} 2$ & $\mathbf{X 3}$ & \\
\hline Quail & 0.22 & 0.00484732 & 10.5 & 5.73642 & -9.61573 & $-9.75 \mathrm{E}-14$ & \multirow{4}{*}{ Hahn et al., 2017} \\
\hline Hen & 0.41 & 0.028573099 & 18 & 10.8715 & -17.8913 & $6.46 \mathrm{E}-14$ & \\
\hline Goose & 0.67 & 0.064067514 & 10.4 & 14.725 & -24.2459 & $1.09 \mathrm{E}-13$ & \\
\hline Ostrich & 2.55 & 0.456017893 & 6.6 & 26.6064 & -46.141 & $2.37 \mathrm{E}-14$ & \\
\hline \multirow{2}{*}{ Titanosaur } & \multirow{2}{*}{$\begin{array}{c}\text { Thickness } \\
{[\mathrm{mm}]}\end{array}$} & \multirow{2}{*}{$\mathbf{V}[\mathbf{L}]$} & \multirow{2}{*}{$\mathrm{d}[\mathrm{mm}]$} & \multicolumn{3}{|c|}{ Load point } & \multirow{2}{*}{ Source } \\
\hline & & & & $\mathbf{X 1}$ & $\mathbf{X} 2$ & $\mathbf{X 3}$ & \\
\hline Tama & 1.495 & 2.50516882 & 167.01 & 41.75 & 72.3131 & 3.09E-09 & $\begin{array}{l}\text { Hechenleitner et al., } \\
2016 \mathrm{~b}\end{array}$ \\
\hline Boseoung & 1.765 & 2.639751625 & 171.47 & 42.8675 & 74.2487 & $-6.77 \mathrm{E}-15$ & $\begin{array}{l}\text { Huh \& Zelenitsky, } \\
2002\end{array}$ \\
\hline Auca & 1.39 & 1.352853804 & 137.22 & 34.3 & 59.4093 & $-1.62 \mathrm{E}-14$ & $\begin{array}{l}\text { Grellet-Tinner, } \\
\text { Chiappe \& Coria, } \\
2004\end{array}$ \\
\hline Toteşti & 1.75 & 1.19220506 & 126.5 & 31.625 & 54.7761 & $2.62 \mathrm{E}-14$ & $\begin{array}{l}\text { Grellet-Tinner et al., } \\
2012\end{array}$ \\
\hline Sanagasta & $1.2-7.95$ & 2.53576055 & 169.188 & 42.297 & 73.2606 & $5.49 \mathrm{E}-14$ & $\begin{array}{c}\text { Grellet-Tinner \& } \\
\text { Fiorelli, } 2010\end{array}$ \\
\hline
\end{tabular}

1 


\section{Table 2 (on next page)}

Summary of the breaking force tests for each egg model.

BP, break point estimated by regression. D, maximum displacement at the load point. F, inner load force. T\#, test number. 


\begin{tabular}{|c|c|c|c|c|c|c|c|}
\hline Model & $\mathrm{T} \#$ & $\mathrm{~F}[\mathrm{~N}]$ & $\mathrm{D}[\mathrm{mm}]$ & Model & $\mathrm{T} \#$ & $\mathrm{~F}[\mathrm{~N}]$ & $\mathrm{D}[\mathrm{mm}]$ \\
\hline \multirow{6}{*}{ Tama } & $\mathrm{T} 1$ & 1 & 0.5910 & \multirow{5}{*}{ Ostrich } & $\mathrm{T} 1$ & 5 & 1.7410 \\
\hline & $\mathrm{T} 2$ & 2 & 0.7619 & & $\mathrm{~T} 2$ & 10 & 3.3090 \\
\hline & T3 & 3 & 1.1230 & & $\mathrm{~T} 3$ & 2.5 & 0.8963 \\
\hline & $\mathrm{T} 4$ & 4 & 1.4720 & & $\mathrm{~T} 4$ & 7.5 & 2.5420 \\
\hline & T5 & 5 & 1.8120 & & $\mathrm{BP}$ & 7.580065 & 2.5500 \\
\hline & $\mathrm{BP}$ & 4.077752 & 1.4950 & \multirow{5}{*}{ Goose } & $\mathrm{T} 1$ & 0.5 & 0.3736 \\
\hline \multirow{6}{*}{$\begin{array}{c}\text { Sanagasta } \\
\text { (thick eggshell) }\end{array}$} & $\mathrm{T} 1$ & 5 & 0.2934 & & $\mathrm{~T} 2$ & 0.2 & 0.1517 \\
\hline & $\mathrm{T} 2$ & 10 & 0.5857 & & $\mathrm{~T} 3$ & 1 & 0.7295 \\
\hline & T3 & 50 & 2.8980 & & $\mathrm{~T} 4$ & 1.2 & 0.8675 \\
\hline & $\mathrm{T} 4$ & 100 & 5.7960 & & BP & 0.919825 & 0.6700 \\
\hline & T5 & 150 & 8.7950 & \multirow{5}{*}{ Hen } & $\mathrm{T} 1$ & 0.25 & 0.1575 \\
\hline & $\mathrm{BP}$ & 136.09665 & 7.9500 & & $\mathrm{~T} 2$ & 0.5 & 0.3114 \\
\hline \multirow{5}{*}{$\begin{array}{c}\text { Sanagasta } \\
\text { (thin eggshell) }\end{array}$} & $\mathrm{T} 1$ & 1 & 0.4560 & & $\mathrm{~T} 3$ & 0.75 & 0.4621 \\
\hline & $\mathrm{T} 2$ & 2 & 0.8959 & & $\mathrm{~T} 4$ & 1 & 0.6096 \\
\hline & $\mathrm{T} 3$ & 3 & 1.3210 & & BP & 0.666208 & 0.4100 \\
\hline & $\mathrm{T} 4$ & 4 & 1.7340 & \multirow{5}{*}{ Quail } & $\mathrm{T} 1$ & 0.05 & 0.1515 \\
\hline & $\mathrm{BP}$ & 2.73 & 1.2000 & & $\mathrm{~T} 2$ & 0.1 & 0.2946 \\
\hline \multirow{5}{*}{$\begin{array}{c}\text { Auca } \\
\text { Mahuevo (egg } \\
\text { levels 1-3) }\end{array}$} & $\mathrm{T} 1$ & 1 & 0.4935 & & $\mathrm{~T} 3$ & 0.15 & 0.4306 \\
\hline & $\mathrm{T} 2$ & 2 & 0.9523 & & $\mathrm{~T} 4$ & 0.025 & 0.0769 \\
\hline & T3 & 3 & 1.3830 & & BP & 0.07477 & 0.2200 \\
\hline & $\mathrm{T} 4$ & 4 & 1.7920 & & & & \\
\hline & $\mathrm{BP}$ & 3.0424 & 1.3900 & & & & \\
\hline \multirow{6}{*}{ Toteşti } & $\mathrm{T} 1$ & 1 & 0.2400 & & & & \\
\hline & $\mathrm{T} 2$ & 3 & 0.7200 & & & & \\
\hline & $\mathrm{T} 3$ & 5 & 1.1800 & & & & \\
\hline & $\mathrm{T} 4$ & 7 & 1.6300 & & & & \\
\hline & T5 & 10 & 2.2800 & & & & \\
\hline & $\mathrm{BP}$ & 7.5836250 & 1.7500 & & & & \\
\hline \multirow{6}{*}{ Boseong } & $\mathrm{T} 1$ & 1 & 0.1825 & & & & \\
\hline & $\mathrm{T} 2$ & 2 & 0.3639 & & & & \\
\hline & $\mathrm{T} 3$ & 3 & 0.5442 & & & & \\
\hline & $\mathrm{T} 4$ & 4 & 0.7234 & & & & \\
\hline & T5 & 10 & 1.7760 & & & & \\
\hline & $\mathrm{BP}$ & 9.9240465 & 1.7650 & & & & \\
\hline
\end{tabular}

1 


\section{Table 3 (on next page)}

Results of FEA on Sanagasta egg models with different eggshell thicknesses. 


\begin{tabular}{|ccc|}
\hline $\begin{array}{c}\text { Eggshell thickness } \\
{[\mathrm{mm}]}\end{array}$ & $\begin{array}{c}\text { Dissolution } \\
{[\mathrm{mm}]}\end{array}$ & $\begin{array}{c}\text { Displacement at the } \\
\text { load point }[\mathrm{mm}]\end{array}$ \\
\hline 7.95 & 0 & 0.29 \\
6.26 & 1.69 & 0.39 \\
4.58 & 3.38 & 0.56 \\
2.89 & 5.06 & 0.87 \\
2.47 & 5.48 & 1.05 \\
2.04 & 5.91 & 1.42 \\
1.62 & 6.33 & 1.78 \\
1.2 & 6.75 & 2.14 \\
\hline
\end{tabular}

1 